\title{
HOW ATHLETES UNDERSTAND THE IMPACT OF SPORTS ON THEIR PSYCHOSOCIAL DEVELOPMENT, THE PROBLEMS THEY FACE AND THE SUPPORT THEY NEED
}

\section{A qualitative research analysis}

\author{
Maria Georgiou, Costas S Constantinou, Manos Stefanakis, Efthimis Kioumourtzoglou \\ University of Nicosia, Cyprus
}

\section{KEY WORDS}

Athletes' Experiences Athletes-Centered Model Qualitative Research

\section{ABSTRACT}

There is evidence to suggest that athletes face multiple challenges during their careers from injuries, to pressure from parents, competition, lack of support, and so forth. A psychologist is important for helping the athlete overcome individual difficulties and succeed. This study is focusing on understanding the role of sports on athletes' psychosocial development, the challenges they face, and the psychological support they need from the athletes' perspective. Through a qualitative research analysis, this study shows that a psychologist can have an overarching role and support not only the athlete but also the athletes' environment such as the coach, parents, and teachers. Reflecting on this finding, an athletecentered model is proposed. 


\section{Introduction}

Y oung athletes engage in sports with the objective of being active, have fun, and gain a positive experience through practicing fundamental skills. Although parents want their children to play so that they "win" (Gould et al., 2002; Seefeldt et al., 1992; Hedstom \& Gould, 2004), the aim of young athletes who engage in sports is to learn and have a good time (Gould et al., 2002; Seefeldt et al., 1992). Being involved in athletic activities has proved to be beneficial both psychologically and physically to young athletes (Purcell et al., 2005). When surveys were carried out to assess sport satisfaction, the results showed that "having fun" is the main reason that most children like to participate in sports (Gould et al., 2002; Seefeldt et al., 1992).

A few studies that examined the effects on those that participated in sports activities showed that sports participation led to improved skills in setting goals, in good time management, in the ability to control emotions, in enhancing cooperation and leadership skills and selfexploration (Hedstrom \& Gould, 2004; Dworkin et al., 2003; Hansen et al., 2003). Additional research findings suggest that teenagers who participate in team sports seem to be happier, show increased self-esteem, experience lower anxiety levels, and a decreased risk of a possible suicidal act (Taliaferro et al., 2008; Malina \& Cumming, 2003). Another study claims that one more benefit of engaging in sports activities is the fact that both male and female athletes look after themselves in a healthy manner. The study suggests that athletes follow a healthy diet which includes eating fruit and vegetables and in addition, they avoid smoking and drug use (Pate, 2000).

Despite the positive outcomes of engaging in sports, athletes face challenges and problems. Athletes face stressful situations. One major stressor for athletes is an injury that could possibly create emotional reactions (Putukian, 2016). According to Putukian (2016), injuries are common in athletes and cause psychological reactions that could affect their thoughts, emotions, and behavior.

Another major challenge for athletes is stress. Research using athletes as participants suggests that the existence of certain factors could protect individuals against the negative effects of stress, rather than the absence of stress. In general, these protective factors could be individual characteristics or found in the individual's environment. External protective factors such as social support refer to the importance of having functional social support systems in athletes' environments. Research findings suggest that individuals who do not have functional social support systems are more prone to experiencing more stress compared to those who have support from family and friends (Moen et al., 2019).

A third stressor is the coach-athlete relationship. The coach-athlete relationship is an important antecedent of the athlete's optimal functioning (Lafreniere et al., 2011). A study by Lafreniere et al (2011) showed that the behavior of coaches towards the athletes enhanced the well-being and satisfaction of athletes. The study highlights the importance of the coach's passion and its positive effect on the athlete's performance. A coach who takes into consideration the athlete's perspective and shows an interest in the athlete's life encourages the athlete to feel closer and more committed to the coach (Deci \& Ryan, 2002). Interacting regularly with athletes and building a good rapport, can enable the coach to enhance performance in athletes (Potrac and Purdy, 2004).

Precompetitive anxiety is cited as a frequent psychological concern in competitive athletes (Hardy, 1997; Martens, Vealey, \& Burton, 1990; Smith, Smoll, \& Schutz, 1990). In the 1970s, Lazarus (1991) argued that stress involved the transaction between the individual and the individual's environment. Lazarus (1991) suggested that human beings are not passive and that they are active agents who appraise their environment. Lazarus (1991) proposed a model that describes how individuals appraise an event and then how individuals evaluate their coping strategies. When the perceived situational demands exceed the individual's perceived ability to meet those demands, the person feels stress and anxiety. Most, athletes experience high levels of anxiety before a football match or before a competition. Athletes need to experience an amount of physical activation in order to be able to compete and perform well. 
However, increased levels of anxiety could hinder success (Hanin, 1995; Yerkes \& Dodson, 1908).

Other stressors could include fear of failure, lack of confidence, inconsistency in performance, and social withdrawal (Undiyaundeye \& Ukwayi, 2015). Such issues could hinder athletic performance and cause frustration and sadness. Consequently, all those factors need to be addressed and dealt within the area of sports.

The presence of a social support network in one's life is beneficial to human nature. Studies using participants from different cultures have shown the benefits of both perceived and received support from significant people in the participants' life (Collins, Dunkel-Schetter, Lobel, \& Scrimshaw, 1993; Dunkel-Schetter, Sagrestano, Feldman, \& Killingsworth, 1996; Morling, Kitayama, \& Miyamoto, 2003).

Social support can be defined as being loved and cared for (Sarason et al., 1990, p. 119). When research focuses on social support in the area of sports, Rees and Hardy (2002) claim that we need first to consider the transactions an athlete engages in. These transactions are related to the significant people in the athlete's life. The important people that the athlete interacts with, who could possibly provide social support include the coach, other players, trainers, friends, family, and psychologists. A coach could be helpful in encouraging good performance. The family could provide emotional support and a psychologist could provide ways to decrease the level of stress and help the athlete cope during a time of injury.

Research findings have indicated that the provision of help enables athletes to cope better. The effects of social support on athletic performance have been documented in various studies. Receiving social support is very important in the life of an athlete as it has shown to play a significant role within the performance context (Rees \& Hardy, 2000; Rees \& Hardy, 2004; Rees, Ingledew, \& Hardy, 1999). Research findings postulated that social support had a positive influence on sports performance in a sample of amateur golfers (Rees, Hardy \& Freeman, 2007). Specific research findings claim that the parental behavior and coach behavior influence athlete decision-making and motivation in a youth-sport context (Keegan, Harwood, Spray, \& Lavellee, 2014; Knight, Berrow, \& Harwood, 2017).

Consequently, due to the possible difficulties encountered in this specific population, the psychological intervention seemed to be a way of providing help to athletes. Historically, psychological support provided to athletes took the form of teaching athletes how to visualize success (Suinn, 1972). However, enhancing performance was not the only concern that athletes face. As stated earlier the problems encountered by athletes include among others, esteem needs, relational issues, and coping with injuries. This led to the need for psychological support that addresses major concerns in the athlete's life. Over the last two decades, the role of sport psychologists has become crucial in the life of athletes (Gee, 2010).

Yet, despite the rapid growth and scientific progress in relation to psychological support, a lot of people in the area of sports hesitate to seek psychological help, even from a psychologist that has specialized in sport psychology (Anderson, Hodge, Lavallee, \& Martin, 2004; Ferraro \& Rush, 2000; Mainar, Curry, Sommers-Flanagan, \& Walsh, 2001; Martin, Kellmann, Lavallee, \& Page, 2002). Ferraro and Rush (2000), wonder why athletes do not seek psychological support when they appear to need it. One of the reasons that have been proposed is the lack of understanding among coaches, athletes, and sporting administrators in relation to what is involved in a psychotherapy session between a client and a sport psychologist (Ferraro \& Rush, 2000; Gardner, 2001; Zakrajsek \& Zizzi, 2007). Some studies have revealed that members of the athletic community equate sports psychologists with psychiatrists and other mental health professionals. Therefore, they would hesitate to book an appointment with a sport psychologist as they might be concerned about being stigmatized as "mentally ill" individuals.

Although the literature above indicate the various challenges athletes are faced with during their career, it seems that there is no evidence in terms of how athletes understand these challenges in light of the psychological support they need. Based on this identified gap, this study aims to answer the question: How athletes understand the 
impact of sports on their psychosocial development, the problems they face, and how psychological support can be a support mechanism. To answer this research question, qualitative interviews have been conducted as per the research methodology below.

\section{Methodology}

\section{Participants}

A total of ten athletes active in Cyprus were invited to participate in an interview. In regards to the kind of sport, they engaged in, eight (8) participants were involved in soccer, while one (1) participant did Taekwondo and 1 Running. Six (6) participants were men and five (5) were women. The age of participants ranged between 19 and 34 with an age average of 25.6. Participants' current family status varied between married, married with children, and single. (See Table 1 below)

Table 1

Participants' profile

\begin{tabular}{|c|c|c|c|c|}
\hline No & Sport & Gender & Age & Family \\
\hline 1 & Soccer & Male & 30 & $\begin{array}{c}\text { Married with } \\
\text { a child }\end{array}$ \\
\hline 2 & Soccer & Female & 26 & Single \\
\hline 3 & Soccer & Male & 25 & Single \\
\hline 4 & Soccer & Male & 20 & Single \\
\hline 5 & Soccer & Male & 34 & $\begin{array}{c}\text { Married with } \\
\text { a child }\end{array}$ \\
\hline 6 & $\begin{array}{c}\text { Taekwond } \\
\text { o }\end{array}$ & Male & 20 & Single \\
\hline 7 & Running & Female & 30 & Married \\
\hline 8 & Soccer & Female & 26 & Married \\
\hline 9 & Soccer & Male & 19 & Single \\
\hline 10 & Soccer & Female & 26 & Single \\
\hline
\end{tabular}

\section{Procedure}

Participants were recruited through sports associations and academies. Sports associations and academies were informed about the study that notified potential participants. Ten participants signed informed consent forms and were interviewed by the first author of the study. The interviews took between 30 and 45 minutes, were transcribed verbatim, coded, and analyzed on the basis of the General Inductive Approach as described below. This study is part of a bigger European project entitled Gamified and Online Activities for Learning to Support Dual Careers of Athletes (GOAL project) and is funded by Erasmus +.

\section{Measures}

A semi-structured interview guide was used. The participants were initially asked to state their age, gender, marital status, and the type of sport they engaged in. Then participants were asked by the researcher to describe their career and to talk about the impact that sport had on their life and then they could talk about their problems and the support they have in the context of their life as athletes. Then the researcher asked the participants' perspective on the role of a psychologist.

\section{Methodology of analysis}

As soon as the ten interviews were transcribed, they were coded and analyzed. The General Inductive Approach (Thomas, 2006) was used as a framework for the coding and analysis of ten interviews and for conceptualizing a model of understanding athletes' needs. The process of coding involved reading the data multiple times, coding based on the questions made, and grouping of the codes together to construct themes. According to Thomas (2006, p.242), inductive coding involves the following: "label the segments of texts to create categories (30-40 categories) $=>$ reduce overlap and redundancy among categories $(15-20$ categories $)=>$ create a model incorporating most important categories (3-8 categories)". Based on Thomas' approach, the aim was to organize the narratives from participants by reducing the volume of information through coding and construction of themes which would provide grounds for conceptualizing a model.

Coding was undertaken by two researchers (first two authors) as per Guest et al's (2006) guidelines in order to ensure the validity of the 
codes. The two researchers coded the interviews separately and then met in order to refine the code and reach consensus. The coding of the ten (10) interviews generated 260 codes which were organized into four main themes (career development, psychological impact, challenges, and support). In order to ensure that the data was enough, the guidelines for achieving data saturation were applied. Data saturation means that the themes are repeated within the data set (in this case the 10 interviews). Francis et al (2010) recommended that ten interviews could be the starting sample, while Guest et al (2006) found that the optimal number was twelve. Constantinou et al (2018) conceptualized a comparative methodology that involved comparing codes from all interviews to conclude that saturation has been achieved. Based on Francis's (2010) recommendation for a starting sample and Constantinou et al's (2017) methodology, the themes derived from the interviews were consistent through-out the data set. Therefore, the data has been saturated and, as a result, it is considered enough to address the research question with regard to how athletes understand the impact of sports on their psychosocial development, the challenges, and the support they need.

The results are presented below in the form of descriptive text and direct quotes from the interviews have been used as supportive references. The purpose of qualitative analysis is to describe the experience of being an athlete with positive and negative outcomes and not to show numbers or percentages. The methodology and the overall presentation of this study were prepared in light of the SRQR (Standards for Reporting Qualitative Research) (O'Brien et al., 2014).

\section{Results}

The coding of the data resulted in four main themes, namely career development, psychological impact, challenges, and support. These themes are analyzed below as sections.

\section{Careers development}

When athletes started describing their life, all of them stated that they were introduced into the area of sports and the sport of their expertise early in life, some of them during later childhood, while others at the beginning of adolescent years. One of the main factors that have contributed to such early induction was the influence of a family member who was interested or had been involved in the same sport already. For example, Participant 4 said that his father was a great influence on him while

Participant 5 advised

my grandfather supported me a lot, he was a soccer player in a particular football team, he guided me through, and his role was highly influential

In a couple of cases, participants were not influenced by a particular individual but they do remember observing other athletes playing or have recollections of themselves playing in the streets with their peers during childhood.

The course of their career from their early induction onwards was similar for all athletes in terms of developing their skills in a sports academy and then moving on to play more professionally. However, there was variation in the actual pathway each athlete followed. More specifically, some of them had their whole career in Cyprus while others, especially those involved in soccer, played in teams in Cyprus, moved to another country, and then returned to Cyprus. Currently, they either continue their career as professionals or coaches.

\section{Psychological impact}

Through-out their career, the participants went through various psychological experiences, which had an impact on how they approached their work and life. They all stated that they had a passion for their sport and that they love what they did.

Participant 5 used words like

I get a huge pleasure from what I do.

Participant 1 said

I love what I do, I take great pleasure from it. It is my life.

One of the most dominant findings from the interviews was that the participants became 
stronger psychologically and that they learned how to cope with difficulties and how to find solutions. For example, the following short statements or words were expressed: gained psychological strength, inspired, learned how to lose, patience, discipline, calmness, competence, became more social and made many friends, respect of others, confidence, autonomous, time management skills, organized, stable, kept away from negative situations. One of the participants stated that football protected him from negative situations and what he implied was the use of drugs and bad company. All these words show that participants consider their experience in sports as a fulfilling experience that has helped them develop psychologically and helped them become more mature.

More specifically, participant 4 stated

I was very shy as a child, I did not form friendships easily. In the sphere of sports, I formed a friendship, football makes you more sociable. As it involves teamwork, you learn how to depend on each other. Also, while playing I can express myself, I can get angry, I can laugh, feel happy, it is a way of expressing myself.

Interestingly, all these positive outcomes that participants have mentioned above, had not necessarily resulted from positive experiences. In fact, many of them described negative experiences which were learning lessons for them. More specifically, some participants experienced pressure and bullying from other athletes and their coaches. Those who had to move to another country to further pursue their career they also experienced racism by other athletes. A couple of participants mentioned that they developed tougher attitudes towards others while a participant explained how he started talking inappropriately as a response to the hard times he had. In addition, some other participants experienced stress, did not have the social life they would like to have, and they had difficulties every time they were injured and had to recover and return as competent as before.

Participant 4 explained

When I had to be away due to injury, I felt that something was missing. When I went back and joined the team I found myself.

\section{Challenges}

The challenges that the participants had were numerous and seem to have added to their psychosocial development in the field of sports. The most recurrent challenges from the interviews were low remuneration, little or no social life, and difficulty in combining sports with university studies. With regard to remuneration, there were more challenges that were pertinent to injuries as many of the athletes had to find the financial means themselves for recovery. In addition, an important aspect of remuneration was the pay gender gap raised by all female athletes.

For example, Participant 2 explained

The money you earn is humiliating as compared to what men make. We would not continue if we did not love playing soccer.

Furthermore, another female participant explained that she experienced gender discrimination when she tried to promote soccer among females. She received comments such as "women should not play soccer" and "women's place is in kitchen washing dishes". There were other challenges, which included a tough schedule, psychological and physical tiredness, and moving from country to country.

Participants found their way around the challenges described above which is what helped them develop psychologically and mature as persons. That is, they accepted that these were challenges that all had. Their passion for their sport seemed to be a driving force for them to remain in the field and work on their development. On this basis, they made sure they had clear goals they wanted to achieve, they focused on their schedule and worked hard. A few examples from participants were:

Participant 2: "I have accepted the situation and I am trying to change it gradually".

Participant 3: "I dealt with all these challenges by having goals and by working hard".

Participant 4: "What kept me motivated was that great feeling I have when I play soccer".

Participant 6: "I am calm and patient. Also, people recognize me in the streets due to my achievements and this keeps me motivated". 


\section{Support}

The support the participants need reflects on the challenges and the psychological impact they experienced. There are four groups of people who could be very supportive. These are coaches, family, psychologists, and teachers.

\section{The role of the coach}

Coaches seem that the play a critical role in athletes' development. Participants understood coaches' role as very important from the beginning of their career so that they could be encouraged, deal with the difficulties, better collaborate with other athletes, gain confidence, deal with injuries and successfully return to their duties.

\section{Participant 1 said}

I had a coach that helped me greatly. He was the reason that I continued to be engaged in sports and to do what I do now.

\section{Participant 2 clarified}

When I played in a specific team the coach was very strict, he used to check on me. He used to visit me and check what time I went to be and I could have seen that, as a challenge, but instead I experienced a lot of stress and I did not have a good time. Later when I joined another team the coach was good and I gained confidence, when though the coach left and another coach took over, I had a difficult time, I felt he had declared war against me... I reached a point that I wanted to stop, he used to put me down, he was saying I was not good enough. Now things are ok, I have support from my coach.

\section{Participant 6 said}

The role of the coach is very important but unfortunately the coach cannot do everything, and the psychologist should help the coach as the coach might not take into consideration the psychological aspect of the athlete's life. Athletes may feel inferior to other colleagues or low self-esteem and this might not help them to perform well. The role of the coach is to help the athlete with these issues.

Participant 7 stated that a good trainer could influence the participation in sports
I started engaging in sports since primary school when I was 11-12 years old. I had a good trainer that encouraged me to take part in athletic games and I became very interested, rather by chance due to that good trainer.

\section{The role of the family}

Family is another context of support which was highlighted by the participants of this study. The family could support the athlete during the early years, during their studies and while recovery from injuries.

Participant 4 highlights the importance of the role of parents

If parents help and support then it is good. The environment should help, should believe that you can make it, should tell you that you are of worth, to give you strength. In my case, my mother gets upset and keeps telling me to stop unlike my father who supports me and gives me strength.

Participant 5 gives an account of his experience with family and implies that the role of parents should be encouraging and empowering

My mother supported me emotionally as well as my grandfather who used to be a football player himself. During the early years, you need the support of parents. My mother helped me by giving me supplements as she was a pharmacist. I grew up without the presence of my father, he abandoned us when I was five. Nowadays, parents push their children to do things that they themselves were not able to do. Parents want their children to accomplish the dreams of their parents. In my case, I achieved what I achieved on my own. I know a lot of athletes that gave up due to parental faults or coach's approach. This is a chain that inhibits the development of an athletic career. Children nowadays do not develop the character that will enable them to become good football players as they do not know how to work hard and discipline themselves. They think that their parents will help and promote them because they know people.

Participant 8 claims that both the family and the coach should be part of an athlete's development 
An athlete needs the support of his/her family in making his/her first steps and then the help from the coach, the coach should support you, trust you, to help you develop. I was lucky that I had good coaches.

Participant 10 describes how her father's change of view towards her made her perform better

My father did not like the idea of me playing football. My mother however used to take me for practice secretly when I was a teenager. My father died when I was 18 , he never came to see me when I played. He used to say that football is not for women. One day he came to one football match that I used to play to see me and when he saw that there were other female players as well, he changed his views. He became my biggest fan., my best supporter and that made me put higher goals.

\section{The role of the psychologist}

Although coaches and the family were mentioned by almost all participants, a psychologist was thought to be instrumental and to have multiple roles. As stated by participants a psychologist could support athletes directly. More specifically, to teach athletes how to accept failures and learn, how to accept their limitations, how to gain confidence and deal with injuries, and how to deal with stress and maintain positive thinking. At the same time, the role of a psychologist was not only confined to providing support for the athlete but it could reach out to encompass coaches and parents. The participants thought that coaches needed support in how to approach athletes and encourage them and how to handle parents, and parents needed help in terms of not exerting unnecessary pressure on their children or having unrealistic demands from the coaches.

The words from Participant 5 are quite illuminating when he comments on the role of the psychologist in relation to the coach and the parents

A psychologist would help $100 \%$. Everything is psychology. When one is not psychologically ready he or she may not do well. A psychologist would help coaches to handle parents who exert pressure on children.
The statement proposed as to the role of a psychologist by Participant 1 is interesting

I believe in the role of the psychologist as he/she can support the athletes when they face difficulties, to help coaches as to how to support athletes and to assist parents and perhaps groups can be formed where athletes gather together and with the help of the psychologist different problems can be solved.

Participant 2 claims that:

A psychologist can help you to develop motives in order to perform better.

Participant 3 comments on the beneficial role of the psychologist in a stressful situation faced by athletes

It is good to have someone to talk with. To have someone to talk about your activity and your worries. I remember before the game I used to be sick from anxiety, I had diarrhea due to stress .. if I had someone to talk with most probably I wouldn't feel sick before the game.

Participant 8 refers to the role of the psychologist in a time of injury

Injuries are very common in athletes and it is at that point that a psychologist is needed. When the athlete has to be away due to the injury and misses on the training he/she feels sad, during that period of time a psychologist can assist the athlete as well as the coach who in turn will help the athlete.

Most of the participants highlighted the importance of having psychological support throughout their career. Interestingly, participants were largely positive towards receiving support through skype because they understood it as convenient, keeping pace with technological development and as it could suit athletes' busy schedules. Only two participants were not positive. One clearly said that he preferred face-to-face support, while the other one explained that he preferred face-to-face first and then skype.

Support from the school and teachers was also mentioned as a couple of participants explained that in some cases their teachers were 
not understanding or were indifferent to the demands of their schedule.

In addition to the four groups of support described above, another important mechanism which could help athletes throughout their career is the financial aspect. Such support could help athletes better develop, would reduce the pressure and stress, and would keep them motivated to continue.

\section{Discussion}

The findings from the interviews highlight the importance, impact, and problems of the sport experience faced by athletes and the role of psychological support. The results have shown that athletes enjoy their sport activity, they have a good time, they have learnt how to be organized, how to set goals, how to cooperate, and increase their self-esteem through their participation in sports which is in line with previous research findings (Gould et al., 2002; Seefeldt et al., 1992; Hedstrom et al., 2004; Dworkin et al., 2003; Hansen et al., 2003; Taliaferro et al., 2008; Malina et al., 2003).

One of the main relational issues reported are either difficulty in the coach-athlete relationship or difficulties with their family. The coach's realistic demands and supportive approach are critical for athletes' success. In addition, pressure from the family and lack of support can shape the athletes' experience. Those issues reported by the participants seem to be issues that have been raised by previous researchers as well (Lafreine et al, 2011; Rees \& Hardy, 2002; Hedstom \& Gould, 2004).

The participants mentioned also the role of the school and particularly the role of teachers in facilitating or preventing the pursue of athletic practice. Although some athletes said that through the athletic activities they could socialize, others stated that due to the hard work they had to put in their sport they had little or no social life. The importance of the athletes' social environment has been highlighted by Moen et al (2019).

The interviews showed that the women athletes face gender pay inequality and they reported feeling bitterness towards such a situation. Women athletes stated that women suffer from discrimination either as amateurs or professionals. The discrimination takes the form of lower pay compared to their male counterparts and sexist comments from society in general and in some instances from their family members. Sports according to them belong to both the sexes and as stated by one of them, society needs to be informed of the role of women in sports.

Along the lines of what has been documented in the literature (Hedstom and Gould, 2004), another problem that the participants face especially the ones that are now in the field of coaching is the demands placed by parents. Current coaches report that they experience parents putting pressure on their children to over competing. The findings from the interviews point out to the fact that parents wish that their child is the new emerging star in football. This parental attitude places a lot of pressure on children and coaches. Young athletes might become anxious and might drop out or they might go to football classes and feel miserable as their intention is very different from their parents' intention.

According to the participants, team sports or sports, in general, are not for every child. One of the main problems addressed by participants who are now into the coaching role is frustration and helplessness as they battle with parents who bring their children to them. Parents seem to put pressure on their children to perform well even though their children might not be able to kick the ball.

Participants also mentioned that based on the above difficulties it would be good for an athlete to have a psychologist in his/her life. Participants stated that psychological support would benefit the athletes, the coaches, and the parents of young athletes. Some participants stated that a psychologist would help the coach to deal with the parents. Another participant suggested group work facilitated by a psychologist. Other studies confirmed the importance of a psychologist in athletes' careers (Gee, 2010) but focused largely on the athlete as an individual or on specific aspects such as injuries. The findings from this study has revealed that a psychologist cannot only help the athletes but also the athletes' environment such as the coach, parents, and the School; eventually supporting the athletes' career.

Another interesting finding was the participants' comments in relation to the use of counseling skype sessions. Participants of this study found the skype session interesting and 
when asked to give feedback from their skype session with the psychologist they stated that it was a very interesting experience. Some said that it was helpful in bringing back memories, in saying things they did not say before, and in expressing feelings and beliefs. As stated by some participants, skype sessions are convenient as they could suit athletes' busy schedules. One participant stated that young athletes are now keen on using technology, therefore a skype session wouldn't be a problem for them. Only a couple of participants said that they would prefer a face-to-face meeting with the psychologist.

\section{A circular model for athlete centeredness}

Based on the coding and analysis of the findings of the interviews, this study has shown that a psychologist is not only for supporting the athlete as an individual but his or her role can reach out to encompass the athlete's environment. On the basis of this important finding, we propose an athlete-centered model (see figure below). It seems that this model is needed for the development and success of athletes. This model proposes that we could place the athlete in the center of development and as we move away from the athlete we reach what is closer to the sport itself. More specifically, starting from the athlete in the center of this approach, the model moves with what is closer to the sport itself. Therefore, athletes need resources to develop such as finances, equipment and time, and a supportive coach. Moving a bit further from the center of the cycle, family and the school could provide a supportive environment for athletes to further develop. From the findings of this qualitative study, it seems that a psychologist could play a critical role in supporting all others (coaches, family, and teachers) including the athlete. A psychologist, thereafter, is at the outer cycle of support not because he or she should be placed as far as possible form the athlete but because it seems that he or she could have an overarching supportive role and be close to all relevant parties.

As stated by the participants, a psychologist can help the athletes and the coaches who deal with athletes. In addition, another role of the psychologist would be to help coaches deal with the parents of young athletes. According to the suggestions made by the participants, the role of the psychologist is not only confined to providing support for athletes but it could reach out to encompass the significant others in the life of the athlete that include the coach and parents.

Future research using bigger samples and combining quantitative and qualitative data could test the effectiveness of this model in athletes' careers. In addition, raising awareness of the role of the psychologist could provide tools for all relevant athletic bodies to introduce psychological intervention in the field of sports.

Figure: A circular model for athlete centredness.

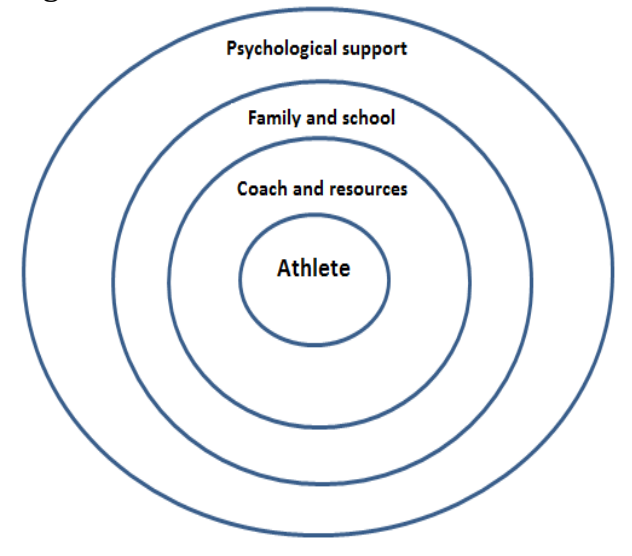

\section{Conclusion}

This study explored how athletes understand the impact of sports on their psychosocial development, the problems they face, and the psychological support they need. In order to answer this research question, an analysis of ten qualitative interviews took place so to understand the athletes' perspective in depth. The study supported the findings from previous research but it showed that the role of a psychologist is crucial and could be overarching in a way to support the athlete but at the same time other parties in the athletes' environment, such as the coach, parents, and teachers. On the basis of this finding, the study is proposing an athlete-centered model for the successful development of athletes by placing athletes in the center and then moving to coach and resources, parents and the school, and the psychologist as the coordinator of support. 
How athletes understand the impact of sports on their psychosocial development...

\section{References}

Anderson, A. G., Hodge, K. B., Lavallee, D., \& Martin, S. B. (2004). New Zealand athletes' attitudes towards seeking sport psychology consultation. New Zealand Journal of Psychology, 33, 129-136.

Collins, N. L., Dunkel-Schetter, C., Lobel, M., \& Scrimshaw, S. (1993). Social support in pregnancy: Psychosocial correlates of birth outcomes and postpartum depression. Journal of Personality and Social Psychology, 65, 1243-1258.

Constantinou, C. S, Georgiou, M., \& Perdikogianni, M. (2017). A comparative method for themes saturation (CoMeTS) in qualitative interviews. Qualitative Research, 17(5), 571-588.

Deci, E., \& Ryan, R. (2000). The 'what' and 'why' of goal pursuits: Human needs and the self-determination of behavior. Psychological Inquiry, 11, 227e268. http:// dx.doi.org/10.1207/S15327965PLI1104_01.

Dunkel-Schetter, C., Sagrestano, L.M., Feldman, P. \& Killingsworth, C. (1996). Social support and pregnancy: A comprehensive review focusing on ethnicity and culture. In G.R. Pierce, B.R. Sarason, \& I.G. Sarason (Eds.), Handbook of social support and the family (pp. 375-412). New York: Plenum Press.

Dworkin, J. B., Larson, R., \& Hansen, D. (2003). Adolescents' accounts of growth experiences in youth activities. Journal of Youth Adolescence, 32(17), 26-27.

Ferraro, T., \& Rush, S. (2000). Why athletes resist sport psychology. Athletic Insight, 2, 9-14.

Francis, J. J., Johnston, M., Robertson, C., Glidewell, L., Entwistle, V., Eccles, M.P., \& Grimshaw, J. M (2010). What is an adequate sample size? Operationalising data saturation for theory-based interview studies. Psychology and Health, 25(10),1229-1245.

Gardner, F. L. (2001). Applied sport psychology in professional sports: The team psychologist. Professional Psychology: Research and Practice, 1, 34-39.

Gee, C. J. (2010). How Does Sport Psychology Actually Improve Athletic Performance? A Framework to Facilitate Athletes' and Coaches' Understanding. Behavior Modification, Vol. 34 (5), 386-402.

Gould, D., Dieffenback, K., \& Moffett, A. (2002). Psychological characteristics and their development in Olympic Champions. Journal of Applied Sport Psychology, Vol, 14(3), 172-204.

Guest, G., Bunce, A., \& Johnson, L. (2006). How many interviews are enough? An experiment with data saturation and variability. Field methods, 18(1),59-82.

Hanin, Y. L. (1995). Individual zones of optimal functioning (IZOF) model: An idiographic approach to performance anxiety. In K. P. Henschen \& W. F. Straub (Eds.), Sport psychology: An analysis of athlete behavior (3rd ed., pp. 103-119). Ithaca, NY: Movement.

Hansen, D., Larson, R. \& Dworkin, J. (2003). What adolescents learn in organized youth activities: a survey of self-reported developmental experiences. J Res Adolesc. 13, 25-56.

Hardy, L. (1997). Three myths about applied constancy work. Journal of Applied Sport Psychology, 9, 277294.

Hedstrom, R. \& Gould, D. (2004). Research in Youth Sports: Critical Issues Status, White Paper Summaries of the Existing Literature. East Lansing, MI: Institute for the Study of Youth Sports, Michigan State University.

Keegan, R.J., Harwood, C.G., Spray, C.M., \& Lavallee, D. (2014). A qualitative investigation of the motivational climate in elite sport. Psychology of Sport and Exercise, 15, 97-107. doi.org/10.1016/j.psychsport.2013.10.006

Knight, C., Berrow, S. R. \& Harwood, C. G. (2017). Parenting in sport. Current Opinion in Psychology, 16, $93-$ 97. doi.org/10.1016/j.copsyc.2017.03.011.

Lafreniere, M., K., Jowett, S., Vallerand, R. J., \& Carbonneau, N. (2011). Passion for coaching and the quality of the coach-athlete relationship: The mediating role of coaching behaviors. Psychology of Sport and Exercise, 12, 144-152.

Lazarus, R. (1991). Emotion and adaptation. New York, NY: Oxford University Press.

Mainar, S. D., Curry, L. A., Sommers-Flanagan, J., \& Walsh, J. A. (2001). Student athlete preferences in seeking help when confronted with sport performance problems. Sport Psychologist, 15, 205-233. 
Malina, R. M. \& Cumming, S. P. (2003). Current status and issues in youth sports. In: Malina RM, Clark MA, editors. Youth Sports: Perspectives for a New Century. Monterey, CA: Coaches Choice.

Martens, R., Vealey, R. S., \& Burton, D. (1990). Competitive anxiety in sport. Champaign, IL: Human Kinetics.

Martin, S. B., Kellmann, M., Lavallee, D., \& Page, S. J. (2002). The development and psychometric evaluation of the Sport Psychology Attitudes-Revised form: A multiple group investigation. Sport Psychologist, 16, 272-290.

Moen, F., Hrozanova, M., Stiles, T., \& Stenseng, F. (2019). Burnout and Perceived Performance Among Junior Athletes-Associations with Affective and Cognitive Components of Stress. Sports, 7, 171 doi:10.3390/sports7070171.

Morling, B., Kitayama, S., \& Miyamoto, Y. (2003). American and Japanese women use different coping strategies during normal pregnancy. Personality and Social Psychology Bulletin, 29, 1533-154.

O'Brien, B.C., Harris, I.B., Beckman, T.J., Reed, D.A. and Cook, D.A., 2014. Standards for reporting qualitative research: a synthesis of recommendations. Academic Medicine, 89(9), pp.1245-1251.

Pate, R. R., Trost, S. G., Levin, S., \& Dowda, M. (2000). Sports participation and health-related behaviors among US youth. Arch Pediatr Adolesc Med, 154, 904-911.

Potrac, P., \& Purdy, L. (2004). Graham Taylor. In R. Jones, K. Armour and P. Potrac (eds.), Sports coaching cultures: From practice to theory. (pp. 21-31). London: Routledge.

Purcell, L. K. (2005). Sport readiness in children and youth. Paediatr Child Health, 10, 343-344.

Putukian, M. (2016). The psychological response to injury in student athletes: a narrative review with a focus on mental health. British Journal of Sports Medicine, 50, 145-148.

Rees, T., \& Hardy, L. (2000). An investigation of the social support experiences of high-level sports performers. The Sport Psychologist, 14, 327 -347.

Rees, T., \& Hardy, L. (2004). Matching social support with stressors: Effects on factors underlying performance in tennis. Psychology of Sport and Exercise 5, 319 -337.

Rees, T., Hardy, L., \& Freeman, P. (2007). Stressors, social support, and effects upon performance in golf. Journal of Sports Sciences 25(1), 33-42.

Rees, T., Ingledew, D. K., \& Hardy, L. (1999). Social support dimensions and components of performance in tennis. Journal of Sports Science, 17,421 - 429.

Sarason, B.R., Pierce, G.R., \& Sarason, I. G. (1990) Social support: The sense of acceptance and the role of relationships. In: Sarason, B.R., Sarason, I.G., and Pierce, G.R. (Eds.): Social Support: An Interactional View, 97-128. New York: Wiley.

Seefeldt, V., Ewing, M., \& Walk, S. (1992). Overview of Youth Sports Programs in the United States. Washington, DC: Carnegie Council on Adolescent Development.

Smith, R. E., Smoll, F. L., \& Schutz, R. W. (1990). Measurement and correlates of sport-specific cognitive and somatic trait anxiety: The sport anxiety scale. Anxiety, Stress, \& Coping, 2, 263-280.

Suinn, R.M. (1972). Behavior rehearsal training for ski racers. Behavior Therapy, 3,519.

Taliaferro, L.A., Rienzo, B., \& Miller, M.D. (2008). High school youth and suicide risk: exploring protection afforded through physical activity and sport participation. Journal of School Health, 78, 545-553.

Thomas, D.R (2006). A general inductive approach for analyzing qualitative evaluation data. American Journal of Evaluation, 27(2), 237-246.

Undiyaundeye, F. \& Ukwayi, G, U. (2015). Counseling Approaches and Sports Issues in Athletics. International Journal of Social Science and Humanities Research, Vol. 3, (1), pp 166-168.

Yerkes, R. M., \& Dodson, J. D. (1908). The relation of strength of stimulus and rapidity of habit-formation. Journal of Comparative Neurology and Psychology, 18, 459-482.

Zakrajsek, R. A., \& Zizzi, S. J. (2007). Factors influencing track and swimming coaches' intentions to use sport psychology services. Athletic Insight, 19, 1-21. 